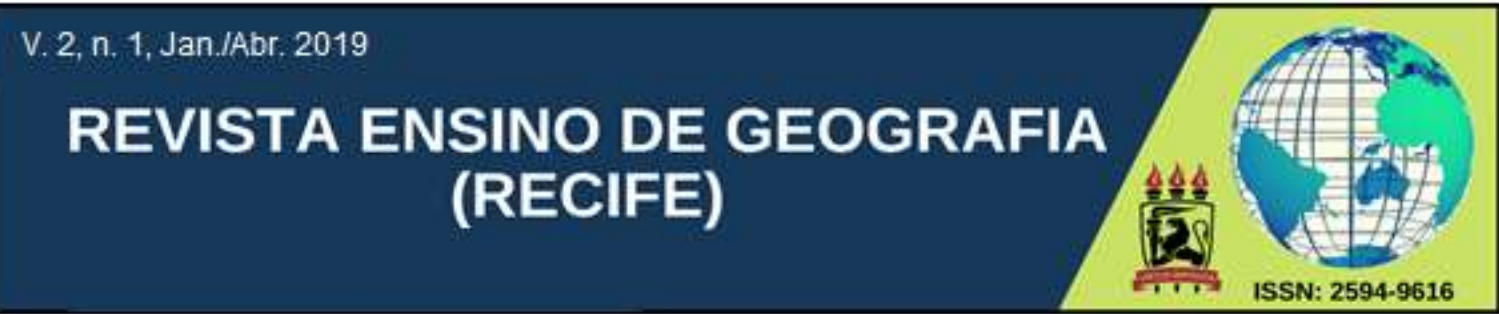

\title{
A IMPORTÂNCIA DAS PRÁTICAS E RECURSOS DIDÁTICO- PEDAGÓGICOS PARA O ENSINO DE GEOGRAFIA
}

\author{
Ana Cláudia Araújo Diniz \\ Departamento de Geografia (UFAM), Geografia Urbana, Humana e Ensino \\ ana_adiniz@hotmail.com \\ ORCID iD: https://orcid.org/0000-0003-1450-3103
}

\author{
Mircia Ribeiro Fortes \\ Departamento de Geografia (UFAM), Geografia Física, com ênfase em Geomorfologia, e \\ Ensino em Geografia \\ mirciafortes@ufam.edu.br \\ ORCID iD: https://orcid.org/0000-0001-7965-6747
}

Artigo recebido em 24/04/2019 e aceito em 26/06/2019

\begin{abstract}
RESUMO: $\mathrm{Na}$ atualidade, contrapondo o que é especificado na legislação educacional do Brasil, o foco do ensino permanece, de maneira geral, visando apenas a formação para o mercado de trabalho, contrariando a perspectiva de educação integral determinada na Constituição Federal e na Lei de Diretrizes e Bases da Educação Nacional, através de um ensino descontextualizado no tocante às diferentes realidades dos discentes no contexto nacional. Nota-se que, neste formato de ensino, prevalecem métodos e recursos antiquados que distanciam os estudantes dos conhecimentos e ambiente escolares, dificultando sobremaneira o processo ensinoaprendizagem. Nessa perspectiva, pretende-se mostrar, através de pesquisa bibliográfica e dos resultados das práticas pedagógicas de estágio supervisionado, as possibilidades de práticas e metodologias promissoras ao ensino de geografia, que podem ser consideradas como facilitadoras no processo ensino-aprendizagem. É notório que o uso de linguagens como filmes, jogos, obras literárias, charges, tirinhas, músicas, bem como aulas de campo (visitas técnicas), possuem potencialidade educacional de contextualização e aproximação dos alunos aos conhecimentos relacionados à disciplina de Geografia iguais ou, muitas vezes, superiores ao do livro didático.

Palavras-chave: Prática de Ensino de Geografia; Recursos Didáticos; Processo de Ensino-Aprendizagem de Geografia.
\end{abstract}

\section{THE IMPORTANCE OF DIDACTIC-PEDAGOGIC PRACTICES AND RESOURCES FOR TEACHING GEOGRAPHY}

\begin{abstract}
Currently, in contrast to what is specified in Brazil's educational legislation, the focus of education generally remains on training for the labor market, contrary to the perspective of integral education determined in the Federal Constitution and in the Law of Guidelines and Bases of National Education, through a decontextualized teaching regarding the different realities of the students in the national context. It is noteworthy that in this teaching format, old-fashioned methods and resources prevail that distancing students from school knowledge and environment, making the teaching-learning process extremely difficult. In this perspective, it is
\end{abstract}


intended to show, through bibliographical research and the results of pedagogical practices of supervised internship, the possibilities of promising practices and methodologies to the teaching of geography, which can be considered as facilitators in the teaching-learning process. It is noteworthy that the use of languages such as movies, games, literary works, cartoons, comics, songs, as well as field lessons (technical visits), have educational potential of contextualization and approximation of students to knowledge related to the same Geography discipline or, often superior to the textbook.

Keywords: geography teaching practice; didactic resources; Geography Teaching-learning process.

\section{INTRODUÇÃO}

A reformulação da Geografia Escolar no Brasil, nas décadas de 1970-80, com a inserção da Geografia Crítica como perspectiva, em substituição da Geografia Tradicional Positivista, herdada do modelo educacional francês ${ }^{1}$, exigiria uma reformulação dos métodos e de recursos didático-pedagógicos utilizados no ensino de Geografia, de forma a possibilitar aos estudantes da Educação Básica as interações e reflexões com as diversas dinâmicas espaciais, visando alcançar o objetivo proposto pela perspectiva da corrente radical, que é o desenvolvimento de um pensamento crítico-reflexivo tão imprescindível aos sujeitos mediante as conjunturas socioespaciais da contemporaneidade.

Os Parâmetros Curriculares Nacionais para o Ensino de Geografia (2000), as Diretrizes Curriculares Nacionais para o Ensino Fundamental e as Diretrizes Curriculares Nacionais para o Ensino Médio (2013) apresentam regulamentações acerca das práticas educacionais no que tange à disciplina da Geografia Escolar. Contudo, de acordo com Pontuschka (2010, p. 112), percebe-se que "a escola da fábrica do século passado ainda está aí e não dá conta da formação desse jovem. Há que se pensar em um ensino que forme o estudante do ponto de vista reflexivo, flexível, crítico e criativo". Isto significa dizer que o foco do ensino permanece apenas na formação para o mercado de trabalho, deixando de lado a formação integral prevista pela Constituição Federal (1988), e pela Lei de Diretrizes e Bases da Educação Nacional (LDB 9.394/1996), sendo então realizado de maneira tecnicista e descontextualizado em relação às diferentes realidades da maioria da população no contexto nacional.

Convém observar que, neste formato de ensino, prevalecem métodos e recursos antiquados que distanciam os estudantes do ambiente escolar, considerando a preponderância do meio técnico-científico informacional, mesmo que excludente. De maneira geral, uma aula

\footnotetext{
1 "Do ponto de vista teórico, é importante registrar a profunda influência europeia sobre o desenvolvimento dessa ciência, com destaque para a presença francesa, pois seus primeiros mestres eram originários da França." (Cf. PONTUSCHKA, 2010, p.114)
} 
onde somente o professor detém o conhecimento e o transmite através da oralidade ou apenas da consulta ao livro didático - uma ferramenta didático-pedagógica importante, mas não a única disponível ao professor -, não ocorre à interação entre professor e estudante no processo de ensino e aprendizagem. Esta prática não se restringe apenas aos professores formados de longa data, fato este observado em muitos profissionais durante as supervisões de estágio em geografia, mas encontra-se também presente nas atividades de graduandos dos cursos de Geografia.

O trabalho aqui apresentado é resultado de pesquisa bibliográfica e de análise das práticas de Aula Simulada, das disciplinas de Estágio Supervisionado, e das regências dos estudantes-estagiários durante o Estágio Supervisionado Curricular, obrigatório para a obtenção do diploma, conforme o artigo $2^{\circ}$, $\S 2^{\circ}$, da Lei $n^{\circ} 11.788 / 2008$. Desta forma, a intenção é contribuir para as reflexões sobre a prática pedagógica no ensino de geografia, e apresentar possibilidades de dinâmicas didático-pedagógicas de construção de conhecimento a partir da criticidade e criatividade, quando se trata do ensino de geografia no cotidiano escolar.

\section{O ENSINO DE GEOGRAFIA: BREVE TRAJETÓRIA HISTÓRICA E CONCEITUAL}

Inicialmente verifica-se a necessidade de explanar sobre a institucionalização da Geografia enquanto ciência na Europa, pois para Moura e Alves (2002) a mesma se configurou como um importante papel para "a estruturação do sistema capitalista e da cristalização do pensamento da burguesia” (p. 310), que acaba por refletir significativamente nas relações espaciais mundiais, alcançando o Brasil, séculos depois, e possui sua influência significativa nas questões educacionais, transmitindo esta cristalização à Geografia Escolar. É importante destacar que a geografia europeia estava orientada em duas frentes principais: a expansão e unificação territorial alemã e a expansão colonial francesa.

Tendo em vista estas configurações, viabilizou-se uma Geografia Escolar voltada para o patriotismo exacerbado, dando base à configuração dos Estados-Nações, surgindo nesse momento a separação educacional entre Geografia Física e Geografia Humana, observada dentro do que se denomina Geografia Tradicional, de cunho acentuadamente positivista, que 
corrobora para a dicotomia na relação sociedade-natureza, pensamento este muito presente no ensino da geografia ainda nos dias atuais.

Em relação à geografia brasileira, a mesma foi institucionalizada apenas no século XX, sendo influenciada significativamente pela geografia francesa até $1960^{2}$, onde se vê o surgimento da Geografia Teorética ou Nova Geografia, que também teve suas limitações, por estar fundamentada nos preceitos positivistas que se encontram justapostos à Geografia Escolar.

\begin{abstract}
O movimento de renovação da ciência geográfica no Brasil, no qual Milton Santos é figura fundamental, fazendo críticas à Geografia 'Tradicional' e Quantitativa terá influência forte no ensino. Surgiram propostas de incorporar no ensino dessa disciplina reflexões da concepção dialética. Nessa linha, é discutida a necessidade de superar abstração do ensino de conteúdos geográficos, e de ter um ensino com papeis politicamente voltados para as classes populares, tendo o aluno como sujeito do processo de ensino-aprendizagem no conhecimento do espaço geográfico. (MOURA e ALVES, 2002, p.310)
\end{abstract}

A Geografia Crítica surge como um movimento de renovação, de acordo com Silva (2007), mas, no entanto, observa-se um distanciamento nos debates entre as universidades e escolas, o que se caracteriza como um movimento divergente entre agentes que deveriam trabalhar dentro de uma mesma perspectiva, considerando-se que deveria haver uma integração entre ambas. Para Silva (2002,p. 314), este cenário é "considerado revelador de uma tradição da Geografia formulada em sala de aula: um saber desprovido de questionamentos sobre o significado, tanto de parte de quem ensina, como de quem aprende".

Como se pode observar, há uma dissociação do ensino escolar geográfico em relação à realidade, da mesma forma que a sua aplicabilidade tem dificultado sobremaneira o processo ensino-aprendizagem. Logo, constata-se que, quando de sua elaboração, os Parâmetros Curriculares Nacionais - PCN's (2000) se baseiam nas propostas da Geografia Crítica, em que o ensino deva partir da realidade do aluno, introduzindo a partir daí os conceitos da geografia, trazendo então uma nova perspectiva para o ensino de geografia e transpondo o que os mesmos classificam enquanto uma "tradição 'bacharelesca"” associada ao ensino, ou seja, há a necessidade de despontar o ensino que não seja apenas tecnicista, mas sim,

[...] uma formação baseada no desenvolvimento de competências cognitivas, sócioafetivas e psicomotoras, gerais e básicas, a partir das quais se desenvolvem

\footnotetext{
${ }^{2}$ CF. MOURA \& ALVES (2002, p. 312)
} 
competências e habilidades mais específicas e igualmente básicas para cada área e especialidade de conhecimento particular. (BRASIL, 2000, p. 11)

Por isso, os conteúdos abordados no ambiente escolar devem possuir um intuito maior que as questões relacionadas ao mercado de trabalho e de formação individualista, mas que o mesmo possa compreender a si mesmo e aos outros em sua plenitude, ou seja, a formação em prol da cidadania. Desta forma, salienta-se a importância de uma discussão acerca dos PCN's. Apesar de não ser este o foco neste trabalho, é necessário enfatizar que os mesmos são uma ferramenta pertinente para a formação integral, uma vez que as propostas, tal como estão organizadas, possuem uma carga política de grande relevância e que pode alterar a configuração da estrutura do currículo escolar. Callai (2001) enfatiza as questões que cercam a educação como mediadora da cidadania ao afirmar que,

[...] muito se tem falado em educação para a cidadania, mas de maneira, muitas vezes, irreal e inalcançável, burocrática, ligada ao positivismo e com soluções técnicas, definida num ou vários objetivos, que no mais das vezes consideram o sujeito - estudante deslocado do mundo em que vive, como se fosse um ser neutro e abstrato. (p.136)

Isto significa que o ensino de geografia deve estar voltado tanto para o desenvolvimento do estudante quanto o seu viver e conviver em sociedade, ou seja, a formação da cidadania não é apenas de cunho meramente político, e sim de uma "cidadania social", que perpassa todas as esferas da sociabilidade, bem como o desenvolvimento do senso crítico. Nesse sentido, o cidadão além de tornar-se questionador em relação às causas e consequências dos problemas, adquire a motivação de analisar/pensar em soluções para o seu cotidiano. Portanto, a Geografia Escolar tem por intuito o dever de

[...] orientar a formação de um cidadão para aprender a conhecer, aprender a fazer, aprender a conviver e aprender a ser. Isto é, deve buscar um modo de transformar indivíduos tutelados e infantilizados em pessoas em pleno exercício da cidadania, cujos saberes se revelem em competências cognitivas, sócio-afetivas e psicomotoras e nos valores de sensibilidade e solidariedade necessários ao aprimoramento da vida neste País e neste planeta. (BRASIL, 2000, p. 11)

Todavia, a Geografia Escolar, ainda nos dias atuais é praticada com hábitos ultrapassados, onde o conteúdo é, frequentemente, evidenciado como algo primordial e exclusivo em relação ao ensino-aprendizagem. Percebe-se, portanto, que a mesma possui um 
grande caráter enciclopédico, voltado simplesmente para a ênfase em memorização de informações acerca do espaço. Conforme Callai (2009),

\begin{abstract}
Nomes de rios, de cidades, acontecimentos tais como erupções vulcânicas, a ocorrência de vendavais, ciclones e tornados, guerras, guerrilhas, incorporação de áreas por outras nações são informações que fazem parte do dia a dia da maioria das escolas. A grande questão, entretanto, é auxiliar o aluno a organizá-las no sentido de entendimento sobre como tais processos naturais e fenômenos atingem a vida das pessoas. (p.101)
\end{abstract}

Isso demonstra a necessidade de desenvolver competências e habilidades dos estudantes com relação a compreender e pensar o espaço geográfico no qual estão inseridos para que, posteriormente, os mesmos assimilem e consigam interpretar a dinâmica de outros espaços e outras sociedades, para que assim tenham uma dimensão escalar espaço-temporal dos fenômenos.

Logo, outro fator que corrobora para a continuidade da aplicabilidade desta Geografia Tradicional é também a negligência a respeito da dicotomia gerada pela academia entre Geografia Física e Geografia Humana. Diante de tal situação, antes de toda e qualquer aproximação de ambas, pode-se mesmo falar em uma preferência ou afinidade que o profissional venha a adquirir ao longo da sua vida acadêmica, considerando que o mesmo, no dia da sua diplomação, sairá apto como professor de Geografia e não de alguma subárea da ciência geográfica. É notório que esta realidade possui considerável interferência no ensino, pois os professores ao maximizarem uma destas subáreas do conhecimento, que geralmente é a Geografia Humana, faz com que o ensino não seja satisfatório.

\title{
3 METODOLOGIA E RECURSOS DO ENSINO DE GEOGRAFIA: O IDEAL VERSUS A PRÁTICA
}

$\mathrm{Na}$ atualidade, o ensino como um todo tem enfrentado desafios, uma vez que a globalização, associada às novas tecnologias da Terceira Revolução Industrial e às telecomunicações, além de gerar uma imensa carga de informações que se replicam a cada segundo, com maior dinamicidade que as encontradas comumente em sala de aula, facilita o acesso, pelo menos para uma parcela considerável da população, a estas informações. Ou seja, mediante as novas configurações socioespaciais do século XXI, bem como os arranjos que evolvem às questões educacionais, verifica-se a necessidade de aplicação de metodologias e 
recursos didático-pedagógicos diversificados no ensino da geografia escolar, objetivando dinamizar o processo de ensino e aprendizagem.

Percebe-se, porém, que os professores, bem como os futuros professores, têm dificuldades em romper com as práticas tradicionais de aula e de desenvolver práticas pedagógicas mais adequadas à pós-modernidade, além das relacionadas à própria ciência geográfica trabalhada no âmbito escolar. Para Pontuschka (2010), o uso "de diferentes linguagens na geografia (obras literárias, cinema, vídeos, fotografias) pode auxiliar na compreensão e crítica da produção do espaço, se o seu uso como mera ilustração for superado" (p. 134).

Em concordância, Castellar \& Vilhena (2012, p. 66) também apontam que "podemos utilizar diversas propostas usando não apenas o formal, mas outros gêneros textuais, literatura, científico, audiovisual, além da linguagem cartográfica", em prol de um ensino que possua uma perspectiva que vá além do que se tem comumente. Vê-se a partir disso, que há uma gama maior de recursos e métodos para o ensino de geografia, fugindo da utilização cotidiana, e tida pelos estudantes como "enfadonha", do livro didático, do quadro e da explicação oral, como, por exemplo, no conteúdo de cartografia.

Isto posto, é notório que o uso de linguagens como filmes, jogos, obras literárias, aulas de campo (visitas técnicas), charges, tirinhas, músicas, entre outros recursos que detêm uma potencialidade educacional, tanto quanto ou maior que o livro didático, servem como recursos didático-pedagógicos propícios, inclusive à interdisciplinaridade ${ }^{3}$, dinâmica, inovação, renovação, interatividade e eficácia do ensino. Há também possibilidade de se trabalhar as potencialidades dos estudantes, bem como as dificuldades dos mesmos, a partir da inserção desses recursos didático-pedagógicos em sala de aula.

Considera-se que os livros didáticos possuem a função e o propósito de colaborar para a formação dos cidadãos, pois de acordo com Choppin (2004, p. 553), o livro didático é um "suporte privilegiado dos conteúdos educativos, o depositário dos conhecimentos, técnicas ou habilidades que um grupo social acredita que seja necessário transmitir às novas gerações". Porém, considerando-se que o mesmo é, de modo geral, baseado em preceitos préestabelecidos, traz consigo uma ideologia na qual o autor está embasado. Assim sendo, muitas vezes, os livros didáticos escolhidos para serem trabalhados em sala de aula configuram-se

\footnotetext{
${ }^{3}$ Esta concepção da interdisciplinaridade é abordada como importante e necessária para o ensino de maneira geral pelos Parâmetros Curriculares Nacionais - PCN's, pelas Diretrizes Curriculares Nacionais - DCN's e até mesmo na exposição da Base Nacional Curricular Comum - BNCC, recentemente configurada.
} 
enquanto elementos de (re)produção do sistema que procura elencar, a partir de conteúdos específicos, as realidades das diversas escalas geográficas, de forma, geralmente, distante da vivência do estudante.

Essa distância se amplia quando analisamos a predileção informativa presente nos livros didáticos, acerca de algumas regiões do país em detrimento das demais, o que faz com que os estudantes sejam privados do conhecimento em relação a sua realidade, ou seja, não são apresentadas as peculiaridades espaciais presentes nas abordagens escalares.

Sendo assim, nota-se que, na utilização do livro didático, é necessária uma reflexão por parte do professor quanto aos conteúdos, bem como de um planejamento que aproxime os temas a serem trabalhados com a realidade da vida cotidiana dos estudantes, como uma forma de realizar contextualizações e analogias. Considerando-se que uma das propostas da Geografia Nova é a superação da mnemônica associada à Geografia Tradicional, que não é de forma alguma eficaz para o ensino de geografia.

Como já mencionado, o livro didático não deve ser o único e exclusivo recurso didático-pedagógico presente no dia a dia do estudante, pois ao ser utilizado como única fonte de conhecimento não é capaz de levar à compreensão acerca das diversas dinâmicas socioespaciais, que dão embasamento para compreender as rugosidades espaciais que se formam a partir das relações sociedade/natureza, e que estão presentes nas mais variadas escalas geográficas.

Ao ser utilizado como único e exclusivo recurso didático-pedagógico, o livro didático não se configura como um recurso que auxilie significativamente para o processo de ensinoaprendizagem, por não colaborar efetivamente para a construção da cidadania, tendo em vista as peculiaridades aqui expostas.

Vesentini et.al. (2007, p. 167), ressalta nossa análise com relação a utilização do livro didático, ao ratificar que, “ao invés de aceitar a 'ditadura' do livro didático, o bom professor deve ver nele, tão somente um apoio ou complemento para a relação ensino-aprendizagem que visa a integrar criticamente o educando ao mundo", ou seja, romper com a reprodução dos conteúdos ali existentes sem qualquer possibilidade de reflexão ou construção de hipótese, como se este fosse o único e exclusivo recurso cabível para o ensino, onde o mesmo é empregado, geralmente para leitura em sala, ou para a reprodução do conteúdo escrito no quadro para o caderno, quando não há livro disponível para todos. 
Um dos problemas recorrentes nas aulas é a ineficácia da utilização do livro didático, na medida em que apenas se memoriza o que está escrito e não se analisam os dados e as informações presentes nos textos didáticos, não criando também outras possibilidades de ampliar o conhecimento escolar. (CASTELLAR \& VILHENA, 2012, p. 139)

Considerando as análises aqui enfatizadas, vislumbra-se, então, a possibilidade e importância da utilização e exploração de inúmeras linguagens no/para o ensino de geografia. Aqui se compreende enquanto linguagem o que Finatti \& Ferraz (2011), enfatizam ao especificar que,

\footnotetext{
Cada arranjo societário humano estabelece em seu meio uma linguagem, entendida como o conjunto simbólico-sígnico viabilizador de comunicação e de interpretação de significados necessários para dar sentido ao viver entre os seus membros, além de permitir aos diversos indivíduos entender as regras com as quais um se coloca no contexto social. A linguagem, portanto, [...]...) é um jogo [...] a partir de uma estrutura lógica comunicativa [...]. (FINATTI \& FERRAZ, 2011p. 65)
}

Para o ensino de geografia, que possui dois grandes ramos ou campos de estudo, Geografia Humana e Geografia Física, “faz-se necessário questionar os conteúdos geográficos que estão sendo ensinados e os métodos utilizados perguntando-se sempre se o saber transmitido está realmente a serviço do estudante" (PONTUSCHKA, 2010, p. 132).

Nessa perspectiva, tem-se a pretensão de mostrar as possibilidades de práticas e metodologias promissoras ao ensino de geografia que podem ser consideradas como facilitadoras no processo ensino-aprendizagem. Nota-se a partir das observações realizadas nas disciplinas de Estágio Supervisionado Curricular II, destinado ao ensino fundamental, Estágio Supervisionado Curricular III, voltado para o ensino médio, e Metodologia do Ensino de Geografia, que, grande parte dos estudantes matriculados apresenta resistência em relação às práticas didático-pedagógicas que não estão atreladas ao usual livro didático e/ou ao quadro branco. Além dos próprios "pré-conceitos" com relação ao modo de transmissão dos conteúdos escolares, ainda enfrenta-se as "recomendações" dos professores regentes nas escolas-campo.

As disciplinas de estágio estão curricularmente inseridas após os acadêmicos cursarem as disciplinas pedagógicas, as quais fornecem subsídios para a apropriação da didática necessária para ser aplicada em sala de aula. A partir dos trabalhos desenvolvidos nas disciplinas de estágio e prática de ensino, foi possível observar que, mesmo após as aulas e oficinas pedagógicas, nas quais foram propostas diversas práticas metodológicas, nenhuma 
estratégia sugerida foi utilizada na sala de aula. Porém, os acadêmicos ao serem interrogados sobre as possíveis situações de desmotivação dos estudantes na disciplina de Geografia, mais da metade considera as problemáticas aqui analisadas. Contudo, quando os mesmos estão incumbidos do papel de professor regente, geralmente costumam (re)produzir as metodologias anteriormente criticadas.

Portanto, pretende-se aqui explanar sobre as práticas e metodologias didáticopedagógicas possíveis de serem inseridas no cotidiano das aulas de geografia, de forma a trazer uma aproximação da disciplina com a didática necessária, bem como fazer com que o estagiário/professor tenha a possibilidade de inserir ao conteúdo teórico, a vivência dos estudantes, ou seja, explorar na sala de aula e aplicar nos conteúdos o espaço vivido dos estudantes, para que a ciência geográfica seja um motivo de interesse não apenas disciplinar, mas algo que se possa vislumbrar para a vida em sociedade.

Diante dessas considerações, a seguir são apresentadas algumas possibilidades que podem ser utilizadas no cotidiano escolar.

1. A música como recurso didático

A música é um recurso áudio midiático presente em todas as sociedades, o que difere são os ritmos, que possui em si uma diversidade de intencionalidades, pois a mesma é capaz de trazer consigo uma carga de informações, desde a composição de sua letra até a contextualização no espaço-tempo em que a mesma é lançada na/para a sociedade, sem contar os mais variados estilos. Portanto, a música pode ser utilizada como um recurso didáticopedagógico de grande valia para o ensino, considerando que a mesma pode aproximar os estudantes aos mais diversos conteúdos de geografia.

\footnotetext{
Convivemos com a música ao longo de quase todo o nosso dia a dia, no trabalho, em casa, na rua, em vários momentos estamos cantarolando alguma música que apreciamos. Podemos considerar que a música é um instrumento educador, já que difunde idéias (sic), em letras e sentimentos em melodias. E, por estar presente quase que integralmente na vida de cada um, a música pode se tornar um recurso eficaz na vida escolar e na assimilação dos conteúdos referentes à Geografia. (BASTOS, 2011, p. 45).
}

Ao utilizar a música em sala de aula deve-se adequar o tema ao conteúdo e, previamente, apresentar os objetivos, para que os estudantes possam observar e refletir acerca 
do tema orientado. A música deverá permitir o diálogo com o cotidiano, motivar a criatividade e, sobretudo, desenvolver competências.

Quais as formas possíveis de se trabalhar uma música em sala? Uma das atividades mais básicas com música na educação é a análise dos compositores e da letra da música, observando seus contextos socioespaciais e históricos. É possível analisar as críticas e reflexões que porventura a música queira transmitir, levando à conexão com o tema geográfico da escolha do professor de geografia.

Pode-se citar, como exemplo, a música "Cidadão"4, interpretada pelo cantor Zé Ramalho, em 1979, composta por Lúcio Barbosa em 1978, cenário no qual o Brasil passava por grandes modificações espaciais e políticas. Verifica-se que o compositor procura retratar na letra da música a migração de parte da população nordestina para a Região Sudeste, em um período considerado de seca severa para o semiárido nordestino, à procura de trabalho para conseguir manter-se e auxiliar a família que havia deixado a mercê da escassez de água e a, consequente, falta de alimentos. É pertinente dizer que, a análise da música perpassa a questão da seca e fome e/ou da relação homem/ambiente, pois os migrantes sertanejos são mão de obra sem qualificação, e, por isso, sem opções, com seus direitos cerceados, nos grandes centros urbanos da região centro-sul, onde o poder da mídia mostra, constantemente, apenas o cenário de aridez, miséria, fome, as agruras do sertanejo e o déficit de precipitação como fatores limitantes para o desenvolvimento, e não discute a história política e social regional, a ineficácia das políticas públicas, as desigualdades regionais, as representações simbólicas.

Logo, percebe-se que algumas temáticas ficam sobressalentes ao analisar a música em relação à perspectiva geográfica, pois está se apresenta útil para um trabalho sobre: migrações, urbanização, regionalização, problemas socioeconômicos e ambientais, entre outras temáticas curriculares da Geografia acadêmica e escolar.

\section{Leitura de charges e tirinhas humorísticas}

As charges e as tirinhas humorísticas são recursos visuais que podem ser classificados entre verbais e não verbais, e que tem como objetivo realizar críticas sociais, trazer informação ou animações informativas. Acerca da linguagem verbal e não verbal, Santos et.al. (2014), afirmam que,

\footnotetext{
${ }^{4}$ Cidadão. Disponível em:< https://www.letras.mus.br/ze-ramalho $>$. Acesso em 20/10/2017.
} 


\begin{abstract}
O uso da linguagem verbal que é a escrita ou da fala que é a não verbal como meio de comunicação, apresentam em seu processo, uma interação que é importante para a construção de um todo. Quando falamos com alguém, lemos um livro ou revista, estamos utilizando a palavra como [...], pois através dela, expomos aos outros as nossas idéias (sic) e pensamentos. A linguagem não verbal é outra forma de comunicação em que o código utilizado é a simbologia. Utilizam de todos os meios comunicativos, como placas, figuras, gestos, cores, som, ou seja, através de signos visuais e sensoriais que por si só já produz um a mensagem que quando compartilhada entre os falantes emite uma comunicação. (SANTOS et.al. 2014, p. 33-34)
\end{abstract}

Portanto, nota-se que ambas as linguagens são importantes para a comunicação social. O Brasil possui um leque de chargistas e cartunistas de grande renome, tais como: Alexandre Beck (Armandinho), Carlos Latuff, André Dahmer, Glauco Villas Boas (Folha de São Paulo), Maurício Ricardo Quirino, Ziraldo (criador do Menino Maluquinho), que utilizam as artes visuais como forma de comunicação e, no geral, como uma forma de protesto, quando as mesmas vêm carregadas de "alfinetadas" em relação aos problemas sociopolíticos, ambientais, entre outros.

Nas aulas de Língua Portuguesa, geralmente é utilizado esse gênero textual como forma de trabalhar a análise, reflexão e criatividade dos estudantes, o que não seria diferente com a disciplina de Geografia, onde se tem a possibilidade de dinamização e construção do conhecimento sócio espacial, pois se presume que ao

[..] quebrar as barreiras da compartimentação científica e disciplinar [...] o caráter enriquecedor do uso de outras linguagens nas aulas de Geografia, bem como da interdisciplinaridade para uma análise e reflexão mais profundas e seguras do mundo. (SOUZA \& SOUZA, 2013, p. 306-7)

Analisa-se que, relacionando-se às concepções que envolvem o processo de ensinoaprendizagem dos conteúdos alusivos à disciplina de Geografia, as charges e tirinhas humorísticas podem conduzir os estudantes à percepção e compreensão acerca dos problemas sociais urbanos e rurais, econômicos, políticos e das condições de vida da sociedade, por exemplo, e, por conseguinte, torná-los sujeitos ativos e participantes frente às situações do dia a dia.

3. Aula de campo (visita técnica) 
A aula de campo ou visita técnica é uma importante ferramenta de observação e análise acerca do meio e da interação sociedade-meio, onde se ratifica a importância da relação teoria e prática, ultrapassando tanto a teorização constante, imposta ao ensino de Geografia, quanto os limites físicos da sala de aula. Além disso, outro fator sobrepujante é trazer à tona a importância do conhecimento e das experiências do cotidiano dos estudantes, fazendo com que os mesmos adquiram um olhar crítico em relação ao espaço ao qual estão inseridos.

Ler o mundo da vida, ler o espaço e compreender que as paisagens que podemos ver são resultados da vida em sociedade, dos homens, na busca da sua sobrevivência e da satisfação das suas necessidades. Em linhas gerais, esse é o papel da geografia na escola: Refletir sobre as possibilidades que representa, no processo de alfabetização, o ensino de geografia, passa a ser importante para quem quer pensar entender e propor a geografia [...]. (CALLAI, 2005, p.228)

Nas aulas de campo tem-se a possibilidade, através do auxílio de mapas, cartas ou plantas, de realizar observação direta do espaço geográfico, ou melhor, a leitura espacial da realidade, frequentemente não perceptível.

Dessa maneira, as aulas de campo representam a concretização do conhecimento teórico adquirido em sala, que juntamente com o conhecimento prévio de mundo dos estudantes, será analisado, observado e criticado. No entanto, a aula de campo tem que possuir um propósito, caso contrário à mesma configurar-se-á apenas como uma saída do ambiente escolar, ou seja, um simples passeio. Por isso, o professor deve estabelecer, primeiramente, o objetivo da aula de campo para os estudantes, e deixá-los ciente da importância para a construção do conhecimento científico.

\section{Os jogos e a ludicidade}

Os jogos lúdicos são excelentes estratégias para trabalhar as habilidades e a imaginação dos estudantes em sala de aula. É um elemento facilitador de ensinoaprendizagem que permite desenvolver qualquer conteúdo de geografia, principalmente por ser atividade que, geralmente, permite o trabalho em grupo, o que colabora significativamente para a integração social dos estudantes, estimula o desenvolvimento cognitivo e amplia a concentração. O professor ao propor e conduzir uma atividade lúdica deverá pensar em ações que potencializem o raciocínio geográfico, principalmente daqueles que possuem dificuldades 
de aprendizagem. Castellar \& Vilhena (2012, p. 44), reiteram que os jogos são importantes para "a inclusão dos alunos que têm dificuldade de aprendizagem, pois eles terão de pensar, analisar possibilidades de ação e criar estratégias, o que contribui para melhorar o raciocínio".

Verifica-se que, além das questões que envolvem a ludicidade e a facilitação do processo ensino-aprendizagem dos conteúdos, também há a viabilização do desenvolvimento em conjunto de atividades que fortaleçam a "formação cidadã", ou seja, a colaboração e o respeito para com o próximo e a sociedade em geral.

Outra ênfase que se pode dar aos jogos de acordo com Finatti \& Ferraz (2011, p. 62), é a possibilidade de articulação com o desenvolvimento do raciocínio-lógico, que "se manifesta amalgamada com uma série de elementos (táticas, estratégias, blefes, induções e até aleatório da sorte)", onde estes acabam por potencializar e/ou se aprimorar nos estudantes. Tendo em vista estas especificidades Brotto (1999), explicita que,

\footnotetext{
Por meio dos jogos, a criança aprende a dominar e conhecer as partes do seu corpo e as suas funções, a orientar-se no espaço e no tempo, a amar a arte, a natureza, a manipular e a construir, a desempenhar os papeis necessários para as futuras etapas da sua vida, a elaborar as suas fantasias e seus temores, a sentir suas tensões, a saber, perder e ganhar, em suma ela pode desenvolver as suas múltiplas inteligências. (BROTTO, 1999, p. 132)
}

Alguns jogos, que apresentam certa dinâmica, podem ser adaptados aos conteúdos de geografia por possuírem alguma associação mesmo que distante (imagem e ação), e outros podem ser inclusive confeccionados (quebra-cabeça, jogo de trilha, caça-palavras, dominó, jogo da memória, bingo, cruzadinha), de acordo com a necessidade do conteúdo a ser ministrado ou reforçado em sala, pois consoante a Finatti \& Ferraz (2011, p. 85), existe "a possibilidade de realizar a transposição das dinâmicas do jogo para processos que ocorrem na vida social é provavelmente [...] um bom artifício didático para o ensino de conceitos da Geografia como o de território". Sem contar o fato de que esta metodologia corrobora significativamente para uma interação e integração dos estudantes.

\section{Os filmes e documentários}

Os filmes e/ou documentários são recursos valiosos à educação em relação à disciplina de Geografia, pois os mesmos conseguem trazer, sendo longa ou curta metragem, a retratação espaço-temporal de fatos históricos ou atuais que alteraram ou alteram significativamente as 
dinâmicas espaciais. Contudo, há uma preocupação com o emprego destes recursos audiovisuais em sala de aula, pois em decorrência da carência e das diversas problemáticas que envolvem o ensino nas escolas brasileiras, principalmente as públicas, os mesmos podem vir a serem usados muitas vezes como uma "solução", ou mesmo como uma substituição de profissionais, pois “coloca-se um videocassete para funcionar e... pronto! Todos os problemas estão resolvidos (?)." (BARBOSA, 2013, p.109). Sendo assim, estes recursos apesar de apresentarem suas benesses, necessitam de objetivo e planejamento prévio mediante a temática proposta a ser trabalhada em sala, pois

O papel do filme na sala de aula é o de provocar uma situação de aprendizagem (...). Nessa perspectiva, é preciso inserir o(s) filmes(s) no enunciado didático que se pretende trabalhar (temas, conceitos, periodizações e configurações espaciais) e constituir buscas de interpretações balizadas em procedimentos com referências múltiplas - o saber escolar adquirido e o saber do mundo vivido - para permitir um diálogo mais amplo com e entre os estudantes. (BARBOSA, 2013, p.112)

A partir do exposto, entende-se que os filmes/documentários podem ser usados como recursos didáticos para exposição de uma temática para análise geográfica. A título de exemplo, cita-se o filme "Tempos Modernos", lançado em 1936, onde Charles Chaplin encena as vivências, experiências e o cotidiano mundial, após as profundas transformações do espaço geográfico, bem como a organização das relações de trabalho, posterior a Revolução Industrial, e seus desdobramentos socioespaciais.

Mas, o recurso por si só não serve como base teórica acerca de qualquer temática da disciplina, mas sim como forma construtiva e didática de revelar aos estudantes a dinâmica socioespacial ao longo do espaço-tempo e sua importância enquanto parte operante destas dinâmicas.

\section{As obras literárias}

A Literatura, embora seja componente curricular trabalhado na disciplina de Língua Portuguesa, pode se articular à disciplina de Geografia, principalmente a literatura brasileira. Através dos autores como Raquel de Queiroz, Euclides da Cunha, José Lins do Rêgo, Lima Barreto, Graciliano Ramos, João Guimarães Rosa, Ariano Suassuna, tem-se o retrato das distintas realidades no Brasil a partir dos escritos dos autores, às vezes de uma forma cômica, 
às vezes mais dramática, com o intuito de chamar a atenção do leitor para determinados contextos excluídos socioeconomicamente.

O trabalho com obras literárias demanda análise biográfica do autor, a fim de compreender acerca do estilo da escrita e temas do autor em questão, bem como do lócus artístico, histórico e geográfico em que transcorre o enredo da obra, pois estes detalhes podem situar o leitor em relação às ideias e ideais da obra.

[...] a relação entre a análise do discurso literário e a ciência geográfica permite a construção do entendimento entre a produção ideológica a partir dos elementos constitutivos da cultura e das relações dialéticas com as experiências dos sujeitos no cotidiano dos mesmos. Apontamos o discurso literário como significativo para a compreensão sócio-espacial (sic) e histórica, não de forma isolada, mas articulada entre a ontologia do ser social e as experiências ficcionais que revelam aspectos sombreados e não nítidos do cotidiano para os sujeitos. (SILVA, 2014, p.85)

Por exemplo, na obra "Os Sertões", Euclides da Cunha (jornalista) narra os acontecimentos da duradoura Guerra de Canudos. A obra procura figurar a realidade do país e a diversidade populacional que o compunha. O livro é particionado em três: Parte I: é realizada uma descrição ambiental detalhada, o que revela um considerável estudo geográfico do meio; Parte II: há uma descrição em relação ao homem, sua vida e costumes, ou seja, o autor realiza um estudo voltado à Antropologia e Sociologia; Parte III: há um estudo historiográfico acerca da Guerra de Canudos, que resultou no genocídio de uma população, uma tentativa do Império do Brasil de mostrar seu poderio e tentar apagar a memória da maior resistência ao regime imperial. Logo, a obra traz em si conhecimentos não apenas geográficos, mas também um profícuo trabalho interdisciplinar entre as disciplinas de Geografia, Sociologia e História.

Em última análise quanto aos recursos didático-pedagógicos disponíveis para o ensino de Geografia, constata-se que profissional da educação deve programar e organizar todo e qualquer recurso didático, para que o mesmo dê sentido às aulas e reforcem os conteúdos, não sendo utilizado apenas como forma de distração, sem uma função e objetivo relacionado.

Souza \& Souza (2013), afirmam que "nenhuma técnica, recurso, atividade ou conteúdo, dinamiza ou 'salva' uma aula por si só" (p. 303). O professor precisa dominar o conteúdo que pretende desenvolver em sala, isso é imperativo. Só assim, um professor consegue potencializar o aprendizado dos estudantes através dos recursos escolhidos. 


\section{CONSIDERAÇÕES FINAIS}

Há de se ponderar que não se deve propor uma homogeneização do ensino da disciplina de Geografia, uma vez que temos um país com leque de diversidades sociais, econômicas, culturais e naturais, tanto local, regional e nacionalmente, e isso interfere significativamente no ensino em cada uma destas localidades, pois de acordo com Callai (2001, p.135), "Um programa oficial pronto e organizado para se adequar/aplicar em todas as escolas passa por cima das contradições existentes na sociedade de um modo mais amplo, e da diversidade que existe nos níveis regionais".

Devido esta realidade, o professor necessita de liberdade para conduzir seu planejamento e sua dinâmica, bem como seu cotidiano em sala de aula, ou seja, o profissional de educação tem necessidade de autonomia para realizar sua tarefa docente de forma críticoreflexiva, a qual está intimamente associada à formação da cidadania.

Parece claro que a utilização de novas linguagens, bem como de recursos didáticopedagógicos variados, auxiliam na construção de conhecimentos da geografia escolar, sob a ótica da sua relevância social e cultural, bem como para ser compreendida como uma disciplina necessária para o exercício da cidadania. Para tanto, o professor de Geografia necessita desenvolver sua práxis levando em consideração os novos conceitos de Geografia, tanto ciência quanto disciplina escolar, construindo e adaptando seus métodos e práticas às necessidades do mundo contemporâneo e, principalmente, de seus estudantes e de seu desenvolvimento como cidadão crítico-reflexivo.

Tendo em conta a gama de componentes curriculares da disciplina de Geografia, os recursos como a música, os jogos, os filmes, as charges e tirinhas, a aula de campo e as obras literárias, se bem embasados, e até mesmo sincrônicos com o livro didático, podem ser trabalhados em diversos contextos, aprimorando as aulas, tornando-as mais significativas e mais próximas da realidade dos estudantes.

Outro ponto fundamental é a resistência dos futuros docentes de Geografia, no que diz respeito ao desenvolvimento de práticas educacionais que se desvencilhem da repetida aula com livro didático, aula expositiva tradicional e leituras, mostrando que, mesmo antes de sair do âmbito da universidade, a (re)produção do sistema de ensino-aprendizagem já está sendo ratificado. Muitas vezes os acadêmicos utilizam-se dos discursos que, até pouco tempo, eram 
os que eles criticavam em relação aos seus professores: os procedimentos didáticos enfadonhos realizados para o processo ensino-aprendizagem.

Em última análise, há necessidade de que todos os profissionais da educação se oportunizem em busca de uma aproximação e um aprimoramento com outras linguagens, bem como tenham a autonomia para tal. Pois se acredita que esta aproximação e aprimoramento viabilizarão aos profissionais da educação formas mais dinâmicas para se compreender o espaço geográfico em diversas escalas.

\section{REFERENCIAS}

BARBOSA, J. L. Geografia e cinema: em busca de aproximações e do inesperado. In: CARLOS, A. F. A. (Org.). A geografia na sala de aula. São Paulo: Contexto: 2013.

BASTOS, A. P. Recursos didáticos e sua importância para as aulas de Geografia. In: Conhecimento Prático: Geografia. São Paulo, n. 37, maio 2011, p. 44-51.

BRASIL. Constituição Federal de 1988. Promulgada em 5 de outubro de 1988. Disponível em: < http://www.planalto.gov.br/ccivil_03/constituicao/constituicao.htm > Acesso em: 20 de junho de 2019.

.LDB: Lei de diretrizes e bases da educação nacional: Lei n ${ }^{\circ}$ 9.394, de 20 de dezembro de 1996, que estabelece as diretrizes e bases da educação nacional. Disponível em:

<http://www.planalto.gov.br/ccivil_03/leis/19394.htm> Acesso em: 20 de junho de 2019. 2000.

. Parâmetros Curriculares Nacionais: Ensino Médio. Brasília: MEC/SEF, p.1-23,

.. Ministério da Educação. Diretrizes Curriculares Nacionais Gerais da Educação

Básica. Brasília: MEC, SEB, DICEI, 2013. Disponível em:

$<$ http://portal.mec.gov.br/index.php?option=com_docman\&view=download\&alias=15548-dc-n-educacao-basica-nova-pdf\&Itemid=30192 > Acesso em: 20 de junho de 2019.

.. Ministério da Educação. Diretrizes Curriculares Nacionais para o Ensino Médio. rasília: MEC, SEB, DICEI, 2018. Disponível em:

<http://portal.mec.gov.br/index.php?option=com_docman\&view=download\&alias=32621 cne-sintese-das-diretrizes-curriculares-da-educacao-basica-pdf\&Itemid=30192 > Acesso em: 20 de junho de 2019.

BROTTO, F. O. Jogos cooperativos: se o importante é competir, o fundamental é cooperar. Santos-SP: Re-Novada, 1999.

CALLAI, H. C. A Geografia e a escola: muda a geografia? Muda o ensino? In: Terra Livre. São Paulo, n. 16, p. 133-152, 1 sem., 2001. 
Estudar o lugar para compreender o mundo. In: CASTROGIOVANNI A.C. (Org.). Ensino de Geografia: práticas e textualizações no cotidiano. Porto Alegre: Mediação, 2009.

CASTELlAR, S.; VILHENA, J. Ensino de Geografia. São Paulo: Cengage Learning, 2012.

CHOPPIN, A. História dos livros e das edições didáticas: sobre o estado da arte.

Educação e Pesquisa, São Paulo, v. 30, n. 3, p. 549-566, set./dez. 2004.

FINATTI, R.; FERRAZ, C. B. O. Linguagem geográfica do jogo de xadrez: uma aproximação ao conceito de território e ao processo de ensino-aprendizagem. In: NUNES, F. G. (Orgs.). Ensino de geografia: novos olhares e práticas. Dourados, MS: UFGD, 2011.

MOURA, J. D. P.; ALVES, J. Pressupostos teórico-metodológicos sobre o ensino de geografia: Elementos para a prática educativa. Geografia, Londrina, v.11, n.2, p. 309-319, jul/dez. 2002.

PONTUSCHKA, N. N. A Geografia: pesquisa e ensino. In: CARLOS, A. F. A. (Org.). Novos caminhos da Geografia. 5 ed. São Paulo: Contexto, 2010.

SANTOS, B. dos; SANTOS, P. R.; NOVAES, L. M. Práticas de ensino através da linguagem não verbal. In: Revista Eletrônica da Faculdade José Augusto Vieira, Lagarto, ano VII, v.7, Agosto, 2014.

SOUZA, H. R. de; SOUZA, P. P. Q.. O mundo de Mafalda: ensinando e aprendendo Geografia através de outras linguagens. In: PORTUGAL, J. F.; OLIVEIRA, S. S. de; PEREIRA, T. R. D. S. (Orgs.). (Geo)grafias e linguagens: concepções, pesquisas e experiências formativas. 1 ed. Curitiba: CRV, 2013.

SILVA, I. A.; BARBOSA, T. O ensino de geografia e a literatura: uma contribuição estética. In: Caminhos de Geografia. Uberlândia, v.15, n.49 mar/2014. P.80-89.

SILVA, J. L.B. O que está acontecendo com o ensino de geografia? - Primeiras impressões. In: PONTUSCHKA, N.N; OLIVEIRA, A.U de. (orgs.) Geografia em perspectiva: ensino e pesquisa. São Paulo: Contexto, 2002.

VESENTINI, J. W. (et. al). Geografia e ensino: textos críticos. Campinas, SP: Papirus, 2007. 